\title{
Technical Comments
}

TECHNICAL COMMENTS are brief discussions of papers previously published in this journal. They should not exceed 1500 words (where a figure or table counts as 200 words). The author of the previous paper is invited to submit a reply for publication in the same issue as the Technical Comment. These discussions are published as quickly as possible after receipt of the manuscripts. Neither AIAA nor its Editors are responsible for the opinions expressed by the authors.

\section{Reply by the Authors to G. E. Dorrington}

\author{
Arnab Samanta,- $\underset{*}{ }$ Daniel Appelö, $\perp$ and Tim Colonius \\ California Institute of Technology, \\ Pasadena, California 91125 \\ Julian Nott $\underline{\underline{\S}}$
}

Nott Technology, LLC, Santa Barbara, California 93101 and Jeffrey HallI

Jet Propulsion Laboratory, California Institute of Technology, Pasadena, California 91011

\section{DOI: $\underline{10.2514 / 1 . J 050961}$}

In his Technical Comment, Dorrington [1] raises several issues regarding the empirical natural convection correlations that are compared with computational fluid dynamics (CFD) models in our paper [2].

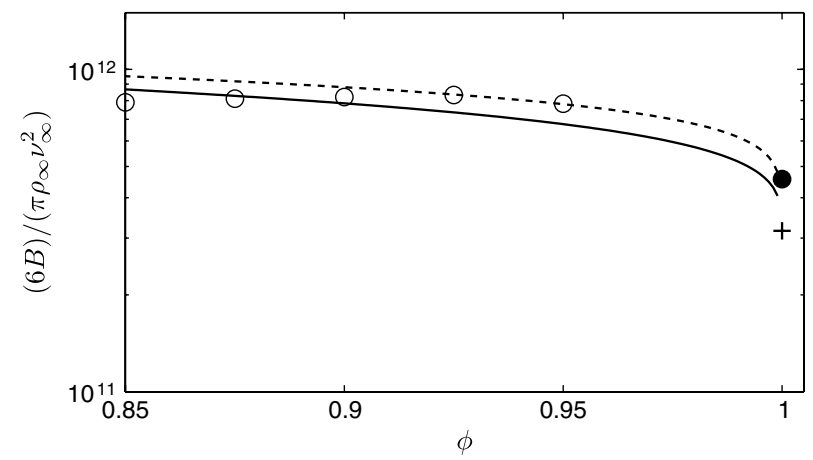

Fig. 1 Effect of gap correlation length scale on net buoyancy of the double-walled balloon. Shown here is the combined correlation for double-walled balloon with the corrected gap correlation (solid line) and the original (incorrect) formula (dashed line). The combined singlewalled correlation [2] is denoted by + . Turbulent simulation results: $k-\omega$ double-walled model (open circle) and $k$ - $\omega$ single-walled model (filled circle; $\phi=1.0$ ) are also shown. Here, nondimensional heat input [2] was $\tilde{Q}=\left(g D^{2} \dot{Q}\right) /\left(\rho c_{p} T_{\infty} v_{\infty}^{3}\right)=5.97 \times 10^{14}$.

Received 19 October 2010; accepted for publication 8 November 2010. Copyright $@ 2010$ by Arnab Samanta. Published by the American Institute of Aeronautics and Astronautics, Inc., with permission. Copies of this paper may be made for personal or internal use, on condition that the copier pay the $\$ 10.00$ per-copy fee to the Copyright Clearance Center, Inc., 222 Rosewood Drive, Danvers, MA 01923; include the code 0001-1452/11 and $\$ 10.00$ in correspondence with the CCC.

*Postdoctoral Scholar, Mechanical Engineering. Member AIAA.

${ }^{\dagger}$ Postdoctoral Scholar, Mechanical Engineering.

Professor, Division of Engineering and Applied Science. Senior Member AIAA.

§President. Senior Member AIAA.

"Senior Engineer, Mobility and Robotic Systems. Senior Member AIAA.
First, for double-walled balloons, we regret that our formula for natural convection in the spherical annulus between concentric spheres promulgated an error from Holman's textbook [3] . Correction of the gap length scale used in the Rayleigh number in this correlation yields the results shown in Fig. 1 for the net buoyancy as a function of gap width $\left(\phi=D_{i} / D_{o}\right)$ for double-walled balloons. The corrected correlation gives a better match with simulation results for balloons with a larger gap size, but a poorer match for smaller gaps and thus does not affect the reported conclusions [2].

Dorrington [1] also suggests the use of alternative internal and external natural convection correlations. For internal correlation, replacing the correlation of Carlson and Horn [4] with that of Hutchins and Marschall [5] only affects the laminar regime, and, as shown in Fig. 2, provides a better match with the laminar simulation results. For external convection, replacing Churchill's [6] correlation as quoted in our paper [2] , with the suggested [1] modified version

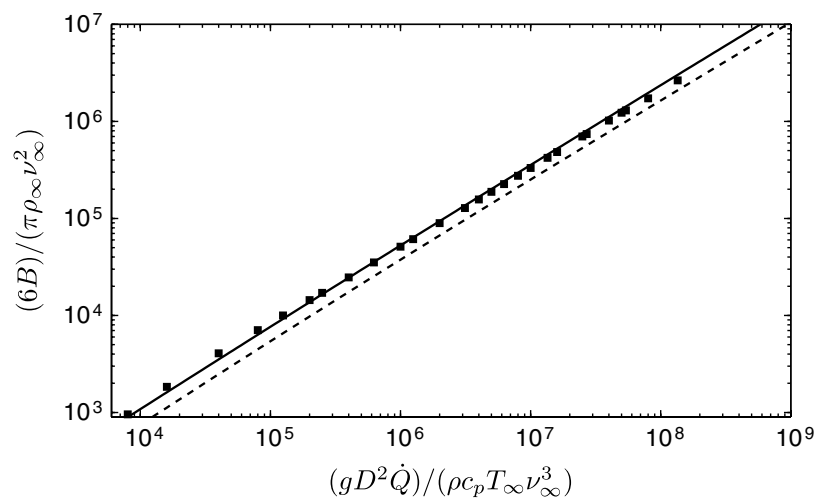

Fig. 2 Net buoyancy versus nondimensional heat input for singlewalled balloons in the laminar regime. Combined correlations using the internal convection correlation of Hutchins and Marschall [ 5 ] (solid line) and that of Carlson and Horn [4] (dashed line) are compared with simulation results (filled square).

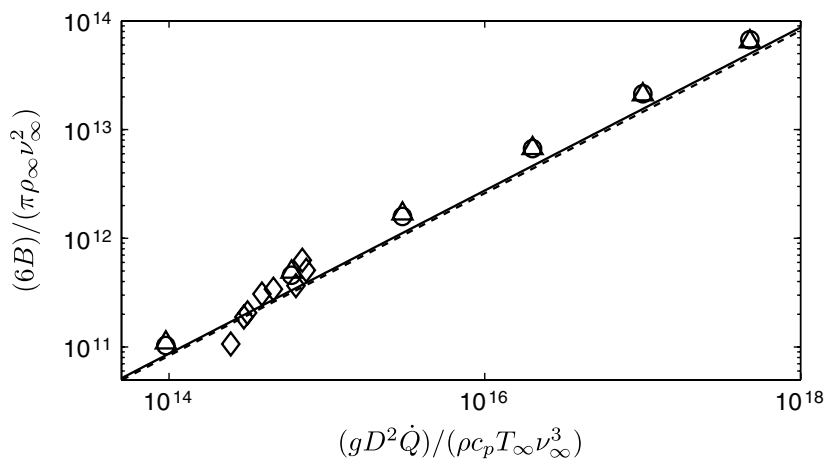

Fig. 3 Net buoyancy versus nondimensional heat input for singlewalled balloons in the turbulent regime. Combined correlations for the net buoyancy versus nondimensional heat input using the external correlation of Churchill [7] (solid line) and that of Churchill [6] (dashed line) are compared with simulations for $k-\varepsilon$ model (triangle), $\bar{k}-\omega$ model (circle), and experiments (diamond). 
(also by Churchill [7]) only affects the turbulent regime. As is shown in Fig. 3, the difference in net buoyancy predicted by the two formulas is quite small. For high Rayleigh numbers approaching the range of applicability to Titan Montgolfieres, our CFD simulations offer no evidence to support the superiority of Churchill's [7] alternative correlation; the shifts in the correlation curves are indeed well within the modeling uncertainties of any simulation employing turbulence models.

\section{References}

[1] Dorrington, G. E., "Comment on "Computational Modeling and Experiments of Natural Convection for a Titan Montgolfiere'," AIAA Journal, Vol. 49, No. 4, 2011, p. 877. doi:10.2514/1.J050886

[2] Samanta, A., Appelö, D., Colonius, T., Nott, J., and Hall, J., "Computational Modeling and Experiments of Natural Convection for a Titan Montgolfiere," AIAA Journal, Vol. 48, No. 5, 2010, pp. 10071015. doi:10.2514/1.45854

[3] Holman, J. P., "Natural-Convection Systems," Heat Transfer, McGraw-Hill, New York, 1997, p. 363.

[4] Carlson, L. A., and Horn, W. J., "New Thermal and Trajectory Model for High-Altitude Balloons," Journal of Aircraft, Vol. 20, No. 6, 1983, pp. $500-507$. doi:10.2514/3.44900

[5] Hutchins, J., and Marschall, E., "Pseudosteady-State Natural Convection Heat Transfer Inside Spheres," International Journal of Heat and Mass Transfer, Vol. 32, No. 11, 1989, pp. 2047-2053. doi:10.1016/0017-9310(89)90111-7

[6] Churchill, S. W., "Free Convection Around Immersed Bodies," Heat Exchanger Design Handbook, Hemisphere, New York, 1983.

[7] Churchill, S. W., "Comprehensive, Theoretically Based, Correlating Equations for Free Convection from Isothermal Spheres," Chemical Engineering Communications, Vol. 24, 1983, pp. 339-352. doi: $10.1080 / 00986448308940090$
D. Gaitonde Associate Editor 